\title{
CARACTERIZAÇÃO FISIOGRÁFICA DA BACIA HIDROGRÁFICA DO CÓRREGO DAS MARRECAS, DRACENA/SP
}

Rafael Brugnolli Medeiros ${ }^{1}$

Angélica Estigarribia São Miguel $^{2}$

Cláudia Aparecida Coronado Brugnolli ${ }^{3}$

\begin{abstract}
RESUMO
A caracterização fisiográfica de uma bacia hidrográfica, diz respeito à análise das características físicas presentes na área, elaborando uma interação entre esses elementos, levando ao conhecimento das possíveis evoluções desses ambientes, bem como, prevenir possíveis degradações. Portanto, a partir do momento que se conhece essas interações, tornam-se possível sugerir formas apropriadas de uso e ocupação da terra, reduzindo os impactos sobre o ambiente. $O$ objetivo desta pesquisa é realizar uma análise fisiográfica da Bacia Hidrográfica do Córrego das Marrecas, localizada no município de Dracena/SP, através de suas características físicas, como geologia, solos, declividade, hipsometria, perfis topográficos e uso e ocupação da terra, buscando assim, uma análise integrada de todo o aspecto físico da bacia. Para a operacionalização da pesquisa, utilizaram-se alguns programas como: Global Mapper 13, ArcGis 10 e Spring, 5.0.6, para mapeamento e conclusão dos perfis topográficos. Os resultados obtidos mostraram que esta área é relativamente plana, porém sua geologia e solos são suscetíveis à erosão, que somado ao aumento do cultivo de cana de açúcar e a degradação que já ocorre na área (poluição devido às lagoas de tratamento), torna esta bacia, vulnerável perante as ações, sejam elas de forma natural ou antrópica. Concluiu-se que a análise dos elementos do ambiente é necessária, pois permite um conhecimento de sua gênese, constituição física, estágio de evolução e cobertura da terra, sendo que estas variáveis precisam ser integradas, obtendo um retrato fiel do comportamento de cada unidade frente sua ocupação, minimizando impactos que podem vir a ser causados.
\end{abstract}

PALAVRAS-CHAVE: Caracterização Fisiográfica; Bacia Hidrográfica; Uso e Ocupação da Terra.

\footnotetext{
${ }^{1}$ Graduado em Geografia e Bolsista CAPES pelo Programa de Pós-graduação em Geografia da UFMS/CPTL; rafael bmedeiros@hotmail.com;

${ }^{2}$ Graduada em Geografia e Bolsista CAPES pelo Programa de Pós-graduação em Geografia da UFMS/CPTL; angelica.esm@hotmail.com;

${ }^{3}$ Bióloga formada pela UNIFADRA-FUNDEC, Dracena-SP; claudia brugnolli@hotmail.com;
} 


\title{
PHYSIOGRAPHIC CHARACTERIZATION OF HYDROGRAPHIC BASIN STREAM MARRECAS, DRACENA/SP
}

\begin{abstract}
The physiographic characteristics of hydrographic basin, relates to the analysis of the physical characteristics present in the area, elaborating an interaction between these elements, leading to the knowledge of the possible evolutions of these environments, as well as prevent possible degradation. Therefore, from the moment it is known these interactions become possible to suggest appropriate forms of use and occupation of land, reducing the impacts on the environment. The objective of this research is to realize a physiographic analysis of Hydrographic Basin of Stream Marrecas, localized in the municipality of Dracena/SP, through your physical characteristics, as geology, soils, slope, hypsometry, topographical profiles and use and occupancy of the land, seeking thus, an integrated analysis of all the physical aspect of the basin. For the operationalization of researchwere utilized some programs such: Global Mapper 13, ArcGIS 10 and Spring, 5.0.6, for completion of mapping and topographic profiles. The results obtained showed that this area is relatively flat, but its geology and soils are susceptible to erosion, which added to increased cultivation of sugarcane and degradation who already occurs in the area (pollution due to the treatment lagoons), makes this basin vulnerable to the actions, whether they be natural or anthropogenic form. It was concluded that the analysis of the environmental factors is necessary, because it allows a knowledge of its genesis, physical constitution, stage of evolution and land cover, and these variables need to be integrated, obtaining an accurate portrayal of the behavior of each front unit their occupation, minimizing impacts that may come be caused.
\end{abstract}

KEY-WORDS: Physiographic Characterization; Hydrographic Basin; Use and Occupation of Land.

\section{CARACTERIZACIÓN FISIOGRAFICOS DE LA CUENCA HIDROGRÁFICA DEL ARROYO MARRECAS, DRACENA/SP}

\section{RESUMEN}

Las características fisiográficas de la cuenca, dice respeto el análisis de las características físicas presentes en el área, elaborando una interacción entre esos elementos, lo que lleva conocimiento de las posibles evoluciones de estos ambientes, así como prevenir posibles degradación. Por tanto, a partir del momento que conocemos estas interacciones se vuelven posibles sugerir formas apropiadas de uso y ocupación de la tierra, reduciendo el impacto en el medio ambiente. El propósito de este búsqueda es realizar una análisis fisiográfica de la Cuenca Hidrográfica del Arroyo Marrecas, ubicada en el municipio de Dracena /SP, a través de sus características físicas, como la geología, suelos, pendiente, hipsometría, perfiles topográficos y el uso y ocupación de la tierra, buscando así una análisis integrado de todo lo aspecto físico de la cuenca. Para operacionalización de la búsqueda, se utilizó algunos programas como Global Mapper 13, ArcGIS 10 y Spring, 5.0.6, para el mapeo y conclusión de los perfiles topográficos. Los resultados obtenido mostró que esta área es relativamente plana, pero su geología y suelos son susceptibles a la erosión, lo que sumado al aumento del cultivo de caña de azúcar y la degradación que ya ocurre en la área (contaminación debido las lagunas de tratamiento), hace que esta cuenca vulnerables a las acciones, tanto si son forma natural o antrópico. Se concluyó que el análisis de elementos del ambiente es necesario porque permite un conocimiento de su génesis, constitución física, fase de evolución y cobertura de la tierra, 
estas variables deben ser integrados, obteniendo un retrato fiel del comportamiento de cada unidad frente su ocupación, minimizando los impactos que puedan causarse.

PALABRAS-CLAVE: Caracterización Fisiograficos; Cuenca Hidrográfica; Uso y Ocupación de la Tierra.

\section{INTRODUÇÃO}

Para o gerenciamento de uma bacia hidrográfica, se torna imprescindível o conhecimento de suas características físicas. Bem como, as diversas formas de uso e ocupação da terra, que podem afetar os recursos naturais, principalmente quando as fragilidades da área são desconhecidas. Dessa forma, estudos integrados que visem diagnosticar as condições do ambiente natural e avaliar a dinâmica no ambiente, podem contribuir para o zoneamento de uma bacia hidrográfica e sua gestão sustentável.

Nesse contexto, diversos estudos propõem a utilização da bacia hidrográfica como unidade de estudo e de planejamento, pois ela integra elementos dos subsistemas, natural, construído, socioeconômico cultural e produtivo, que se interagem entre si e com seu entorno, podendo ser analisado de forma quantiqualitativa. Dessa forma, Botelho e Silva (2004, p. 155) salientam que o valor da bacia hidrográfica como unidade de análise e planejamento ambiental vem crescendo nos últimos anos. Sendo aceitável, considerar de forma integrada, as ações sobre o ambiente natural podendo ou não, alterar o equilíbrio ecológico.

Considerando a bacia hidrográfica a partir de seus elementos naturais, a mesma possui uma série de características que a individualizam e ao mesmo tempo caracterizam sua dinâmica, nesse sentido, Andreozzi (2005, p.38) salienta que as bacias de drenagem estão continuamente sofrendo os processos de modificação do relevo, ou seja, a dinâmica da modelagem fisiográfica é contínua.

A caracterização dos elementos naturais de uma bacia, bem como, a interação de tais informações, contribui para os zoneamentos ambientais. Nesse sentido Mello (1999, p.48) salienta que nos estudos em bacias hidrográficas, o solo, a vegetação e a água são elementos indispensáveis, pois o conhecimento das interações que 
existem entre si e com os outros, permite notar como os mesmos interferem na dinâmica de uma bacia hidrográfica.

Dessa forma, a bacia hidrográfica corresponde a múltiplos elementos interligados e a partir do momento que se conhece essas interações, tornam-se possível propor formas adequadas de uso e ocupação da terra, minimizando os impactos sobre o ambiente.

A Bacia Hidrográfica do Córrego das Marrecas - BHCM, localizada no município de Dracena/SP é um grande exemplo de ambiente com alto índice de área antropizada, pois possui uma grande variedade de usos e ocupações da terra, como diversas lavouras temporárias, hortas, cana de açúcar, eucalipto, seringueira e área urbana, como também há de se notar que grandes partes das matas ciliares do curso principal e de seus afluentes se encontram em estágio avançado de degradação.

Além desses fatores, existem três lagoas de tratamento de água no alto curso do córrego das Marrecas e grande quantidade de lixo acumulado às margens do córrego, que por sua vez, acabam modificando o ambiente, sendo que essas grandes quantidades de poluentes acabam afetando toda a vida aquática.

Através disto, esta pesquisa tem como objetivo realizar uma análise fisiográfica da BHCM se baseando em características físicas desta área, como dados de geologia, solos, declividade, hipsometria, perfis topográficos (longitudinal e transversais) e uso e ocupação da terra, buscando, uma análise integrada de todo o aspecto físico da bacia hidrográfica. Possibilitando assim, auxiliar na indicação práticas conservacionistas adequadas e sustentáveis para esta área, que vem sendo muito degradada ao longo dos anos.

A BHCM tem uma área de $71,80 \mathrm{Km}^{2}$ e encontra-se entre as coordenadas geográficas de $21^{\circ} 25^{\prime} 50^{\prime \prime}$ e $21^{\circ} 31^{\prime} 40^{\prime \prime}$ de latitude $S$ e $51^{\circ} 42^{\prime} 08^{\prime \prime}$ e $51^{\circ} 30^{\prime} 00^{\prime \prime}$ de longitude W como demonstrado na Figura 1.

Figura 1: Localização e Articulação da Bacia Hidrográfica do Córrego das Marrecas, Dracena/SP. 


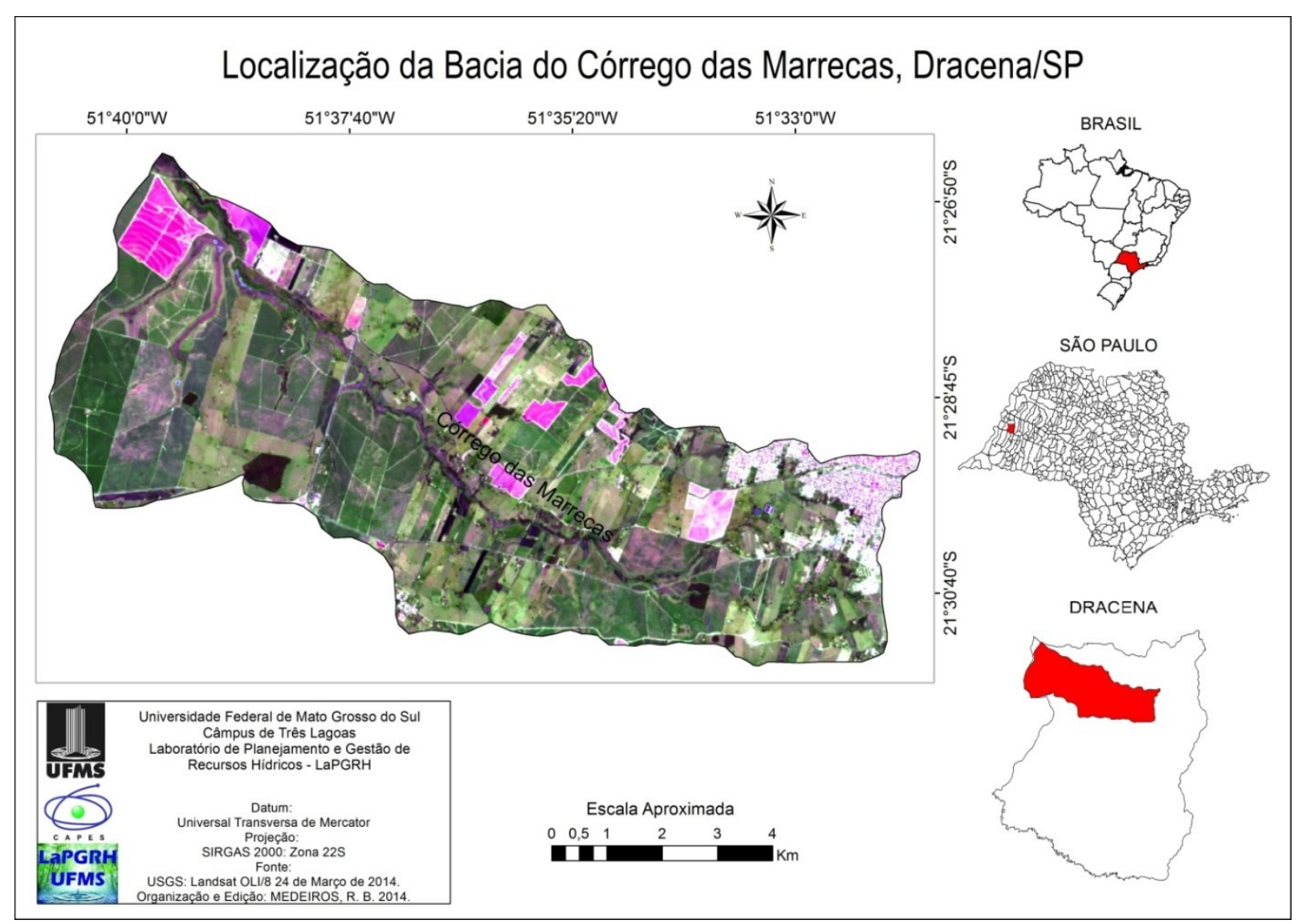

Fonte: USGS - United States Geological Survey.

\section{DESENVOLVIMENTO}

\subsection{METODOLOGIA}

Esta pesquisa foi desenvolvida com base no conceito de ecodinâmica de Tricart (1977) onde propôs que o ambiente fosse estudado pelo seu comportamento dinâmico, ou seja, a partir do entendimento das relações mútuas entre os diversos componentes do sistema e de todos os fluxos de energia e matéria que entram e saem no ambiente.

A caracterização geológica da área de estudo foi elaborada com o auxílio do ArcGis $10^{\circledR}$, onde na extensão ArcMap 10, gerou-se o mapa geológico do estado de São Paulo na escala de 1:750.000, dados técnicos do Serviço Geológico do Brasil (CPRM). 
A caracterização dos solos da bacia hidrográfica foi elaborada com o auxílio do $\operatorname{ArcGis}^{\circledR} 10$, no mesmo procedimento descrito no parágrafo anterior, utilizando os dados técnicos da EMBRAPA (1999).

Para a elaboração da carta de declividade foi necessário primeiramente, a importação de imagens SRTM - Shuttle Radar Topography Mission, da Embrapa, disponível no site: http://www.relevobr.cnpm.embrapa.br/download/ms/ms.htm, onde foi feito o download da imagem SF-22-V-B para posteriormente, importá-las no programa ArcGis 10, onde através do auxílio da ferramenta Spatial Analyst, em seguida a opção Surface e Slope, foi possível visualizar a porcentagem de declividade na área da bacia hidrográfica em questão.

Inicialmente, utilizou-se a imagem SRTM para gerar as curvas de nível com eqüidistância de 20 em 20 metros, em seguida para gerar a hipsometria foi necessária a utilização de um MDT (Modelo Digital de Terreno) que foi gerado por triangulação irregular da grade (TIN) na ferramenta Tin Management > Create Tin, localizado no item 3D Analyst tools do ArcGis ${ }^{\circledR} 10$.

Para a realização do perfil longitudinal foi usado o programa Global Mapper ${ }^{\circledR}$ 13 e a imagem SRTM, sendo feito o caminho natural do rio principal da sua nascente até a foz, gerando automaticamente o perfil.

Para a realização dos perfis transversais também foi utilizado o programa Global Mapper $^{\circledR} 13$ e a imagem SRTM, sendo traçado perfis próximo ao alto curso, no médio curso e próximo a foz no baixo curso. Este é outro aspecto fundamental na geometria de uma bacia hidrográfica, pois permite observar as variações do relevo e altitude em diversas seções transversais.

Para a elaboração do uso e ocupação da terra foi feita uma interpretação de imagens de satélite Landsat OLI/8 adquiridas gratuitamente no site da USGS - United States Geological Survey, para a delimitação da bacia utilizou a imagem de radar SRTM (Shuttle Radar Topography Mission) do ano de 2000.

No uso e ocupação da terra foram definidas classes temáticas, sendo dividido em: Classe Mata é referente às áreas de reserva legal, matas ciliares e florestas plantadas. Na classe temática água foi classificada todos os corpos d'água. Os solos sem cobertura vegetal ou aquelas terras que estão sendo preparadas para plantio, 
foram classificados como solo exposto. As classes lavoura temporária referem-se às áreas de cultivo temporário, como por exemplo, a cana de açúcar, entre outros. Na classe silvicultura, foi adquiridas amostras de plantio de eucalipto e seringueira. Já a classe temática pastagem foi caracterizada pela presença de gramíneas destinadas ou não para a criação do gado de corte. Na classe área urbana foi classificada as cidades, indústrias, aeroporto, entre outras atividades antrópicas.

\subsection{RESULTADOS}

Segundo os dados obtidos pelo Instituto Geológico do Governo do Estado de São Paulo, a BHCM tem presença de Depósitos Aluvionares. Esses Depósitos Aluvionares constituem em aluviões antigos e recentes encontrados na forma de faixas estreitas e alongadas com altitudes baixas (planícies aluviais e terraços aluviais), ao longo das calhas dos principais rios. Atualmente a maior parte dessas planícies encontra-se submersas pelos reservatórios das barragens Três Irmãos e Promissão, no Rio Tietê; bem como, no Rio Paraná, pela represa de Jupiá e pelo lago de Porto Primavera (CETEC, 1999, p.17).

Com relação ao solo da $\mathrm{BHCM}$, foi encontrado o solo Argissolo Vermelho/Amarelo que são solos minerais, que tem como características diferenciais a presença do horizonte $B$ textural de argila de atividade baixa ou alta conjugada por bases baixa ou caráter alitico.

Um fator que surge como uns dos principais para que se possa elaborar uma caracterização fisiográfica é a declividade, uma vez que a mesma exerce influência direta sobre os demais elementos presente no ambiente.

Na carta de declividade Figura 2 e Tabela 1, foi feita a partir da metodologia de Lepsch (2002), identificou quatro classes de declividade, 0-3\%, 3-6\%, 6-12\% e 12$20 \%$. 
Figura 2: Declividade da Bacia Hidrográfica do Córrego das Marrecas, Dracena/SP.

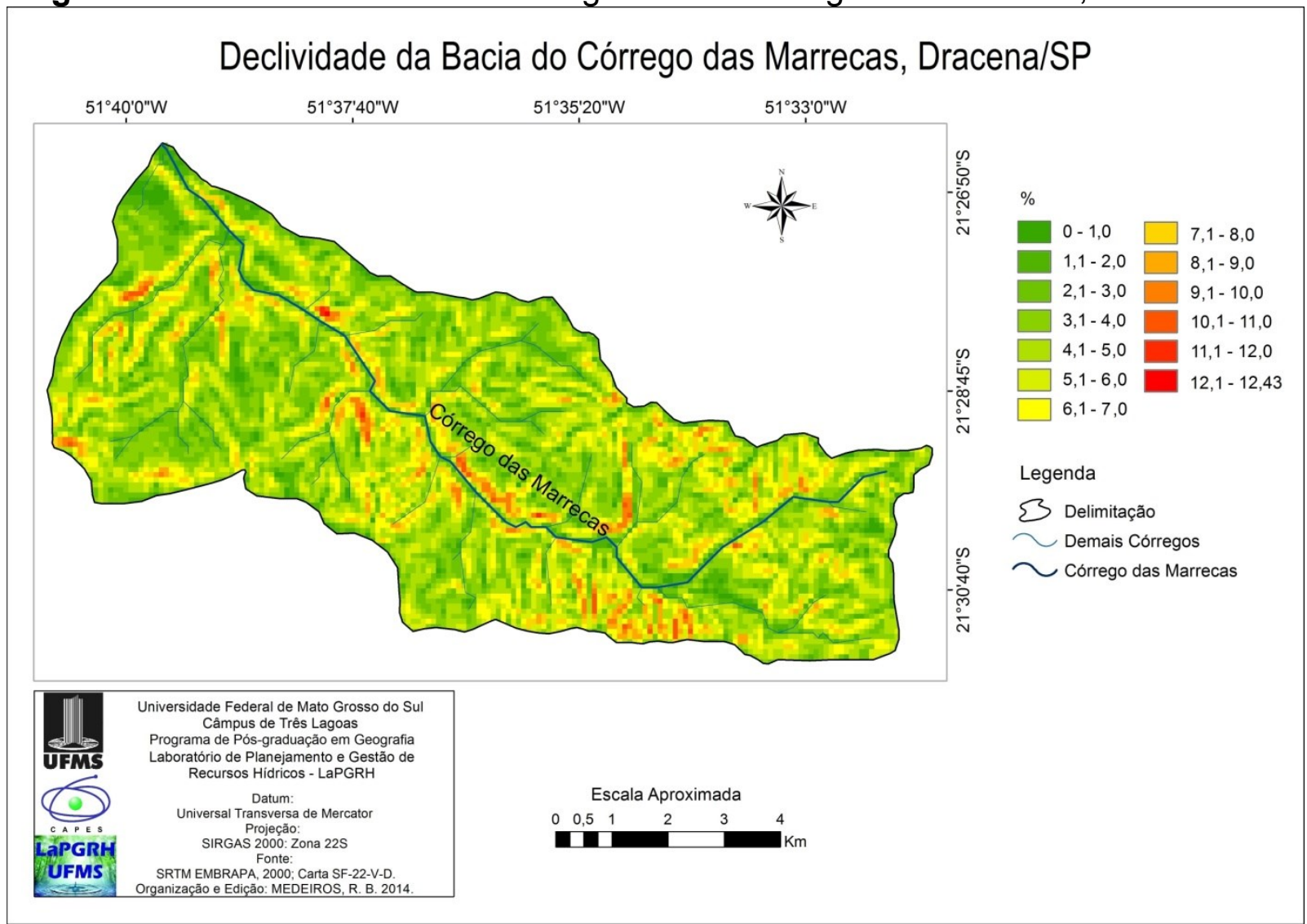

Fonte: EMBRAPA, SRTM - Carta SF-22-V-D.

Tabela 1: Classes de Declividade e Facilidade na Ocupação Rural na BHCM.

\begin{tabular}{c|c|c|c|l}
\hline $\begin{array}{c}\text { Classes } \\
\text { de } \\
\text { Declive }\end{array}$ & Classificação & $\begin{array}{c}\text { Área } \\
\left.\mathbf{( k m}^{2}\right)\end{array}$ & $\begin{array}{c}\text { Área } \\
\mathbf{( \% )}\end{array}$ & \multicolumn{1}{|c}{ Facilidades na Ocupação Rural } \\
\hline 0,0 a 3,0 & Muito Suave & 18,62 & 25,93 & Apto a qualquer uso agrícola \\
\hline 3,1 a 6,0 & Suave & 39,83 & 55,47 & $\begin{array}{l}\text { Depende da subclasse, pois será preciso } \\
\text { ações de controle erosivo ou de melhoria na } \\
\text { fertilidade do solo. }\end{array}$ \\
\hline $\begin{array}{c}6,1 \text { a } \\
12,0\end{array}$ & $\begin{array}{c}\text { Suave } \\
\text { Ondulado }\end{array}$ & 13,31 & 18,54 & $\begin{array}{l}\text { Restrita a agricultura, mas apta para } \\
\text { agricultura moderna desde que use técnicas } \\
\text { de manejo e conservação do solo. Permite } \\
\text { pastoreio, reflorestamento e a manutenção } \\
\text { da vegetação natural. }\end{array}$ \\
\hline $\begin{array}{c}12,1 \text { a } \\
20,0\end{array}$ & Ondulado & 0,04 & 0,06 & $\begin{array}{l}\text { Não permite uso agrícola, somente } \\
\text { manutenção da vegetação original. }\end{array}$ \\
\hline & & 71,80 & 100,00 & \multicolumn{2}{|c|}{} \\
\hline
\end{tabular}

Fonte: Adaptada de Lepsch (2002) e Ramalho Filho e Beek (1995).

Org: MEDEIROS, (2014). 
A classe de declive de 0,0 a $3,0 \%$ é classificada como muito suave, abrangendo uma área de $18,62 \mathrm{Km}^{2}$, ou seja, $25,93 \%$, apta a qualquer uso agrícola, segundo Ramalho Filho e Beek (1995).

A classe de 3,0 a 6,0 é classificada como suave, ocupando uma área de $39,83 \mathrm{~km}^{2}$, ou seja, $55,47 \%$ da área total da bacia. Para Lepsch et. al. (2002), essas áreas com nenhuma ou somente pequenas limitações de uso, apresentam solos profundos, de fácil mecanização e são indicadas para o plantio de culturas anuais, com o uso de práticas simples de conservação do solo.

A classe de 6,0 a 12,0 é qualificada como sendo suave ondulado e ocupa uma área total de $13,31 \mathrm{~km}^{2}$, ou seja, $18,54 \%$ e são indicadas para plantio de culturas anuais, sendo recomendadas práticas de conservação do solo (LEPSCH et. al., 2002).

A classe de 12,0 a 20,0 é classificada como sendo ondulado, porém o máximo de declive que foi encontrado na bacia é de $12,5 \%$, esta classe ocupa apenas $0,04 \mathrm{~km}^{2}$, ou seja, $0,06 \%$ da área total. Segundo classificação de Lepsch et. al. (2002) são áreas com predomínio a problemas de erosão, entretanto, impróprias para culturas anuais e indicadas para culturas perenes, para proporcionar uma proteção maior ao solo.

Juntamente com a carta de declividade e os demais parâmetros apresentados, a carta hipsométrica e os perfis longitudinal e transversais constitui-se numa informação importante, levando em consideração as curvas de nível, como mostrado na Figura 3. Para a compreensão das inclinações, desníveis e altitudes, foram traçados alguns perfis topográficos, como: transversal do alto e baixo curso, assim como o perfil longitudinal que foi elaborado da cota mais alta próximo à nascente até a foz do córrego das Marrecas. As classes hipsométricas foram divididas com equidistância de 20 em 20 metros para uma demonstração mais detalhada do relevo. 
Volume 10, Número 2, 2014

Bacias Hidrográficas, Planejamento e Gestão dos Recursos Hídricos

Figura 3: Hipsometria da Bacia Hidrográfica do Córrego das Marrecas, Dracena/SP. Hipsometria da Bacia do Córrego das Marrecas, Dracena/SP
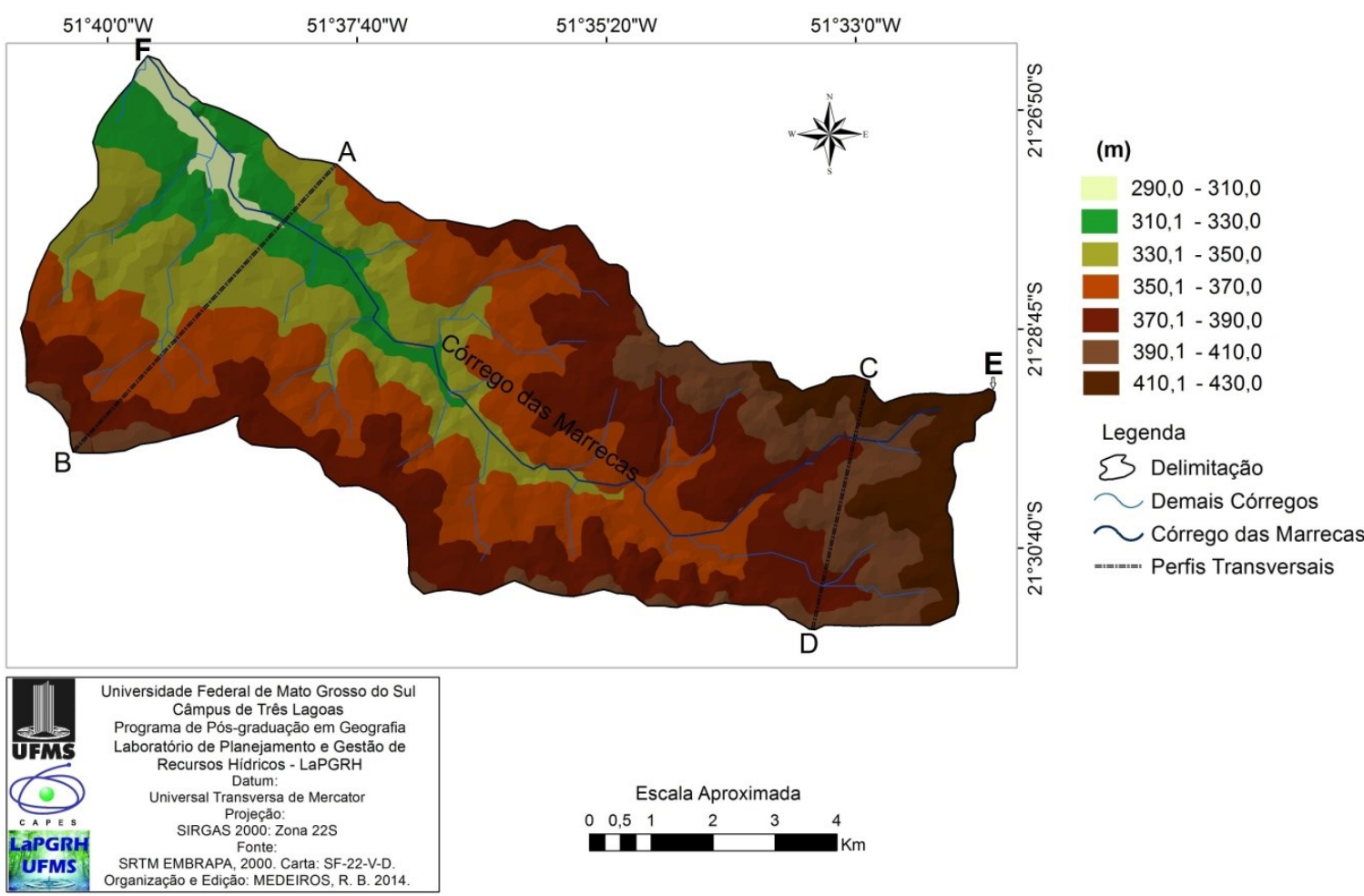

Fonte: EMBRAPA, SRTM - Carta SF-22-V-D.

O canal principal da bacia hidrográfica do córrego Moeda possui aproximadamente 19,95 km de extensão, sua nascente posiciona-se a $420 \mathrm{~m}$ e sua foz no Rio Paraná, a cerca de 300 m, representado um desnível médio de 6,01 m/km na Figura 4.

Figura 4: Perfil Longitudinal da Bacia Hidrográfica do Córrego das Marrecas, Dracena/SP.

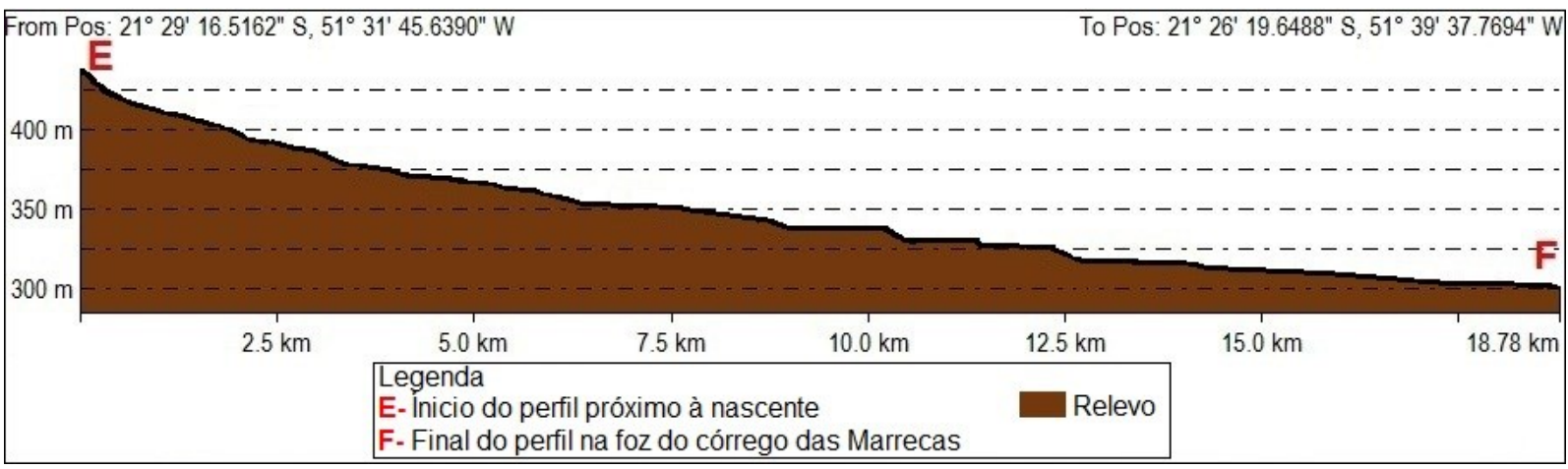


Fonte: EMBRAPA, SRTM - Carta SF-22-V-D.

Com relação ao relevo, no alto e baixo curso da BHCM foram traçado dois perfis transversais, seguindo as cotas mais altas dos divisores de água, conforme a Figura 5 e Figura 6.

Figura 5: Perfil Transversal do Baixo Curso da Bacia Hidrográfica do Córrego das Marrecas, Dracena/SP.

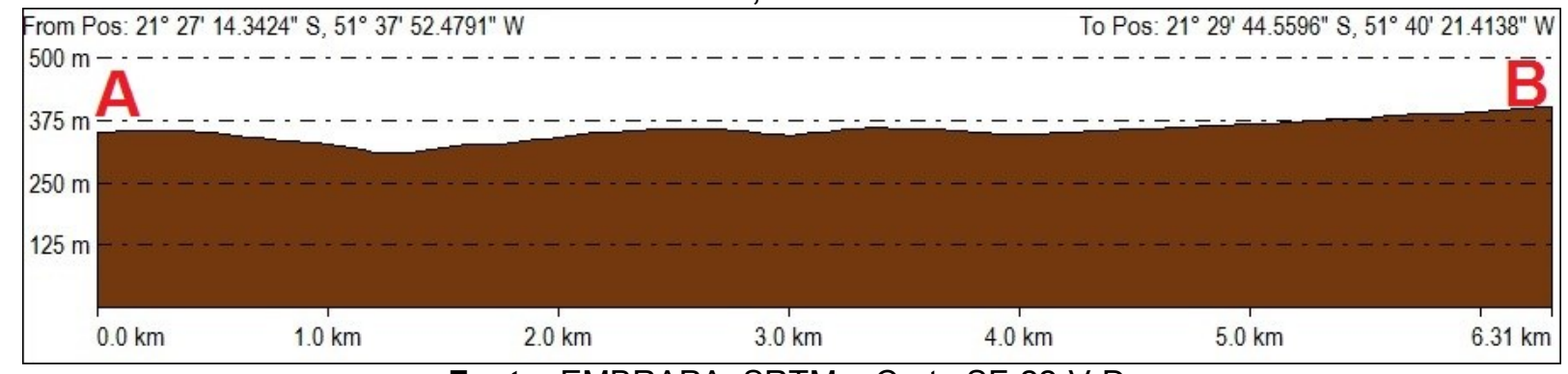

Fonte: EMBRAPA, SRTM - Carta SF-22-V-D.

Figura 6: Perfil Transversal do Alto Curso da Bacia Hidrográfica do Córrego das Marrecas, Dracena/SP.

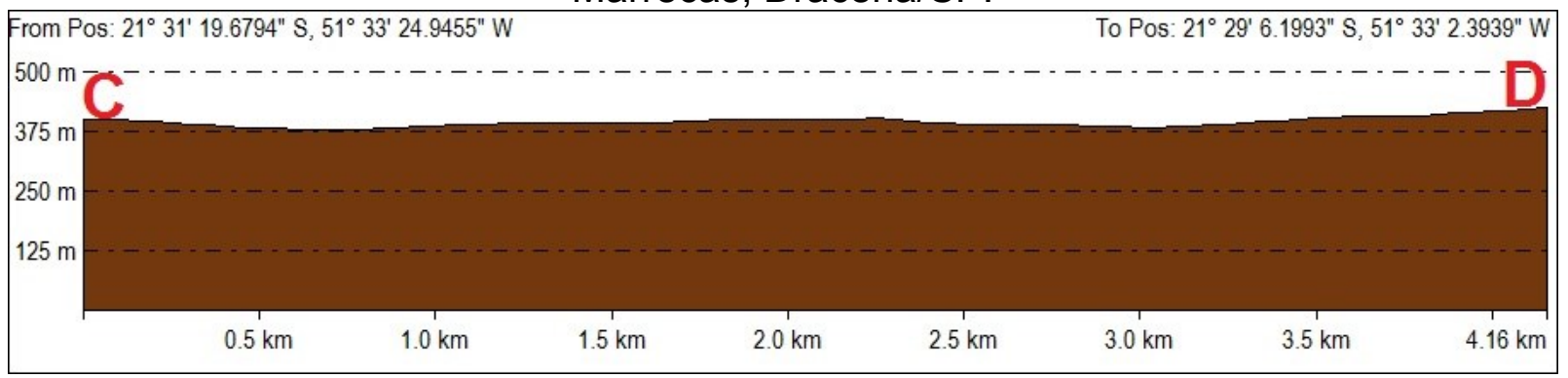

Fonte: EMBRAPA, SRTM - Carta SF-22-V-D.

De forma geral, Tucci e Clarke (1997) afirmam que para minimizar qualquer tipo de impacto devido ao declive e relevo de determinado local, a cobertura vegetal possui um papel prático na absorção dos excessos hídricos, sejam eles de origem superficial ou por meio das precipitações.

Dessa forma, paralelamente a estas variáveis já apresentadas, outro parâmetro de notável importância é destacado, visando à caracterização fisiográfica, esta variável é com relação ao uso e ocupação do solo. Neste sentido, o ano de 2014, Figura 7, foi constatada uma área relativamente grande de lavoura temporária, 
Volume 10, Número 2, 2014

Bacias Hidrográficas, Planejamento e Gestão dos Recursos Hídricos

mostrando estar em uma crescente na região este tipo de cultivo, mas ainda foi predominante a áreas destinadas as pastagens.

Figura 7: Uso e Ocupação da Terra na Bacia Hidrográfica do Córrego das Marrecas, Dracena/SP.

Uso e Ocupação da Terra na Bacia do Córrego das Marrecas, Dracena/SP em 2014

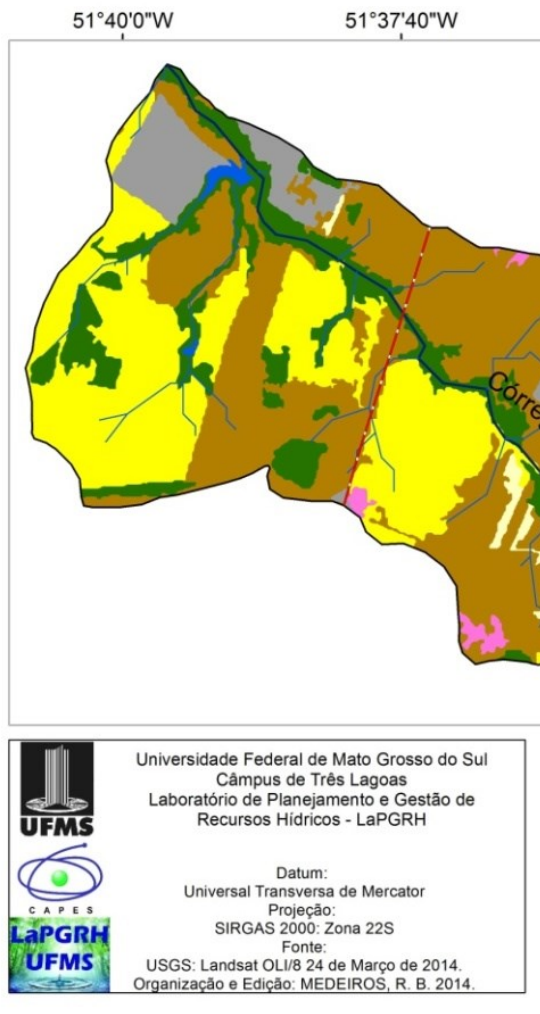
$51^{\circ} 33^{\prime} \mathrm{O}^{\prime \prime W}$

Fonte: USGS - United States Geological Survey.

Na Tabela 2 são apresentados os dados gerados pelo $\operatorname{ArcGis}{ }^{\circledR} 10$, em $\left(\mathrm{km}^{2}\right) \mathrm{e}$ porcentagens (\%) do uso e ocupação da terra no ano de 2014.

Tabela 2: Uso e Ocupação da Terra no ano de 2014.

\begin{tabular}{c|c|c}
\hline Classes & Área $\left.\mathbf{( k m}^{\mathbf{2}}\right)$ & Área (\%) \\
\hline Água & 0,25 & 0,36 \\
\hline Mata & 9,23 & 12,85 \\
\hline Pastagem & 37,45 & 52,16 \\
\hline Silvicultura & 0,88 & 1,22 \\
\hline Lavoura Temporária & 14,66 & 20,42 \\
\hline Solo Exposto & 5,08 & 7,07 \\
\hline Área Urbana & 4,25 & 5,92 \\
\hline & 71,80 & 100,00 \\
\hline
\end{tabular}


Org: MEDEIROS, 2014.

Analisando a Figura 7 e comparando com os dados da Tabela 2, em 2014, a classe Mata representa uma área de 12,85\%. A pastagem se mostrou predominante na área, com um total de $52,16 \%$ da área da bacia, sendo característico na região devido à criação de gado de corte.

A silvicultura teve um percentual de apenas $1,22 \%$ na área, que foram encontradas em manchas dispersas, principalmente no médio curso do córrego das Marrecas. Já a lavoura temporária encontrada ocupou $20,42 \%$ do total, onde grande parte dessa produção é de propriedade das usinas de cana de açúcar existentes na cidade de Dracena e do município a leste, Junqueirópolis.

A classe água na interpretação da imagem de satélite sofre algumas alterações, pois o topo das árvores mascara o curso do córrego, não dando um valor exato da quantidade de água existente na bacia, dessa forma, esta classe apresentou $0,36 \%$ do total da área. Esta classe foi encontrada apenas no baixo curso e no alto curso, onde fica localizada as três lagoas de tratamento de água, Figura 8 e Figura 9 , sendo que esta lagoa acaba interferindo e alterando toda a bacia hidrográfica.

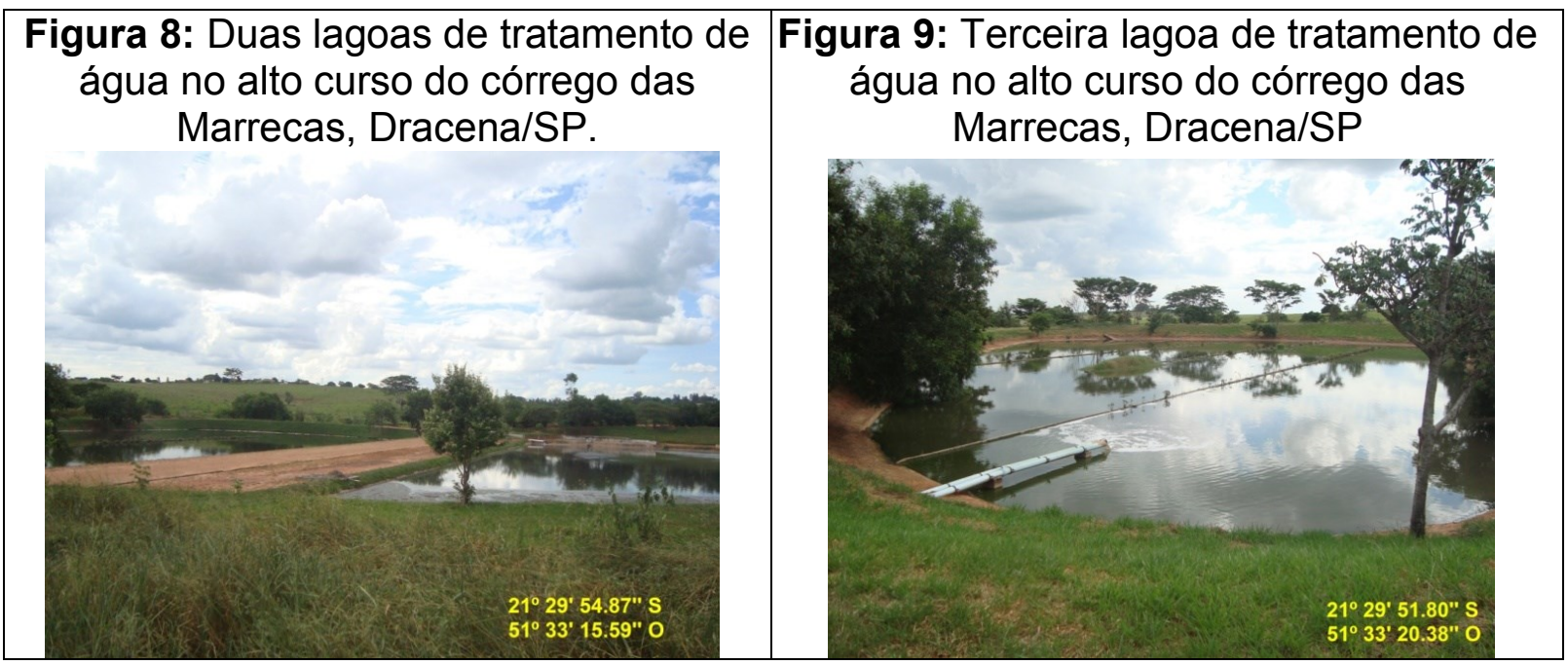

Fonte: MEDEIROS, 2014. 
Com relação à classe de solo exposto, que foi representada por áreas sem cobertura vegetal sendo elas para preparação de terra para novo plantio (Figura 10) ou até mesmo erosões, dessa forma, abrangeu $7,07 \%$ do total da área da bacia.

Figura 10: Solo exposto com um início de plantio de cana de açúcar.

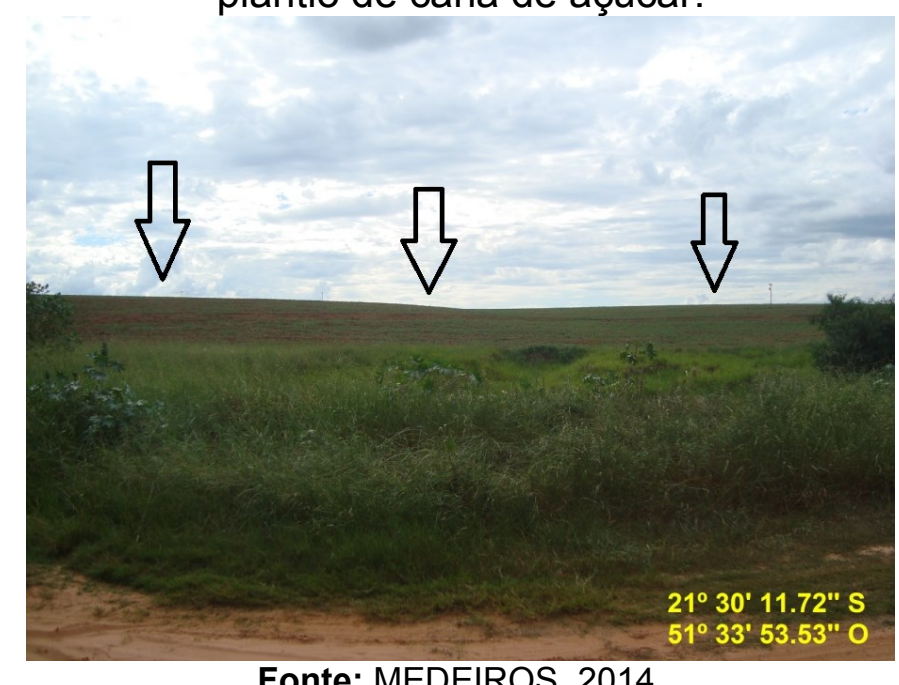

Fonte: MEDEIROS, 2014.

Por fim a classe de Área Urbana, que foi classificada com as cidades, indústrias, aeroporto, entre outras atividades antrópicas, apresentou uma total de $5,92 \%$. Através da ida ao campo, mostraram-se notáveis alguns processos erosivos que em vários locais se encontram em estágios avançados.

\section{CONCLUSÃO}

Concluiu-se que, para uma análise das unidades do ambiente natural é necessário que se conheça sua gênese, constituição física, forma e estágio de evolução, bem como a natureza da cobertura vegetal que se desenvolve sobre ela. Todos estes dados serão fornecidos pela geologia, solo, declividade, hipsometria, perfis topográficos (transversais e longitudinal) e uso e ocupação da terra, sendo que estas precisam ser integradas para que se tenha um retrato fiel do comportamento de cada unidade frente à sua ocupação. 
$\mathrm{Na}$ bacia hidrográfica predominam relevo relativamente plano, sendo classificado como suave segundo sua declividade e são recobertos por Argissolo Vermelho/Amarelo latossolos vermelho amarelo.

Com as saídas de campo e através do mapeamento, nota-se grande quantidade de áreas destinadas às lavouras temporárias, sendo sua principal lavoura, a cana de açúcar, onde nas proximidades da BHCM existem indústrias destinadas a este cultivo, que acabam alterando o escoamento superficial, podendo tanto mitigar, como potencializar ou até gerar novos impactos ambientais.

Notam-se na área, três lagoas de tratamento de água, que por sua vez, acabam lançando degetos no córrego das Marrecas, prejudicando a qualidade e quantidade de suas águas superficiais, nota-se a grande quantidade de lixo nas margens e como também no leito dos recursos hídricos desta bacia hidrográfica.

\section{REFERÊNCIAS}

ANDREOZZI, S. L. Planejamento e Gestão em Bacias Hidrográficas: uma abordagem pelos caminhos da sustentabilidade sistêmica. Tese (doutorado). Instituto de Geociências/Universidade Estadual Paulista - UNESP - Campus Rio Claro: Rio Claro, 2005. 105p.

BOTELHO, R. G. M; SILVA, A S; Bacias Hidrográficas e Qualidade Ambiental. IN: Reflexões sobre a Geografia Física no Brasil. Antônio Carlos Vitte \& Antônio José Teixeira Guerra (Org.). Rio de Janeiro, Bertrand, 2004.

CETEC. Centro Tecnológico de Fundação Paulista de Tecnologia e Educação. CBH-BT - Comitê da Bacia Hidrográfica do Baixo Tietê. Situação dos Recursos Hídricos do Baixo Tietê - UGRH 19. Minuta Preliminar do Relatório Técnico Final. Diretor - CTEC: Wiltevar Verati. Lins, ago. 1999.

CHRISTOFOLLETTI, A. Geomorfologia. São Paulo, Edgard Blücher, $2^{a}$ edição, 1980. 188p.

CPRM - Serviço Geológico do Brasil. GeoBank. Disponível em: <http://www.cprm.gov.br/>. Acesso em: 04 de Abr. 2014.

EMBRAPA. Centro Nacional de Pesquisa de Solos. Sistema Brasileiro de Classificação de Solos. Rio de Janeiro, 1999. 412 p.

IG. Instituto Geológico: Governo do Estado de São Paulo. Geologia Geral. Disponível em: <igeologico.sp.gov.br> Acesso em: 15 de Abr de 2014.

LEPSCH, I. F. Formação e Conservação dos solos. São Paulo: Ofícina de Textos, 2002,178p.

MELLO. N. A. de. Gestão em Bacias Hidrográficas Urbanas para Superação de Comprometimento Ambiental. In: Boletim Paulista de Geografia. N. 76. São Paulo. 1999. p. 23-66. 
RAMALHO FILHO, A; BEEK, K. J. Sistema de avaliação da aptidão agrícola das terras. 3. ed. Rio de Janeiro: EMBRAPA-CNPS, 1995. 65 p.

TRICART, J. Ecodinâmica. Rio de Janeiro. IBGE/SUPREN, 1977. 91p.

TUCCI, C. E. M.; CLARKE, R. T. Impacto das mudanças da cobertura vegetal no escoamento: Revisão. Revista Brasileira de Recursos Hídricos, v.2, n.1, p.135-152, 1997.

USGS - United States Geological Survey. Earth Explorer. Disponível em: <http://earthexplorer.usgs.gov >. Acesso em: 07 de Maio, 2014. 